\title{
openheart The no-touch vein graft for coronary artery bypass surgery preserves the left ventricular ejection fraction at 16 years postoperatively: long-term data from a longitudinal randomised trial
}

\author{
Benny Johansson, ${ }^{1}$ Ninos Samano, ${ }^{2}$ Domingos Souza, ${ }^{2}$ Lennart Bodin, ${ }^{3}$ \\ Derek Filbey, ${ }^{2}$ John D Mannion, ${ }^{4}$ Leif Bojö ${ }^{5}$
}

To cite: Johansson B, Samano N, Souza D, et al. The no-touch vein graft for coronary artery bypass surgery preserves the left ventricular ejection fraction at 16 years postoperatively: long-term data from a longitudinal randomised trial. Open Heart 2015;2: e000204. doi:10.1136/ openhrt-2014-000204

Received 2 October 2014 Revised 19 January 2015 Accepted 20 January 2015

\section{(a) CrossMark}

${ }^{1}$ Department of Clinical Physiology, Faculty of Medicine and Health, Örebro University, Örebro, Sweden ${ }^{2}$ Department of

Cardiothoracic and Vascular Surgery, Faculty of Medicine and Health, Örebro

University, Örebro, Sweden

${ }^{3}$ Karolinska Institute, Institute of Environmental Medicine, Unit of Intervention and Implementation Research, Stockholm, Sweden ${ }^{4}$ Department of Surgery, Bayhealth Medical Center, Dover, Delaware, USA ${ }^{5}$ Department of Clinical Physiology, Central Hospital, Karlstad, Sweden

\section{Correspondence to} Dr Ninos Samano; ninos.samano@orebroll.se

\section{ABSTRACT}

Objectives: To assess the left ventricular heart function and the clinical outcome 16 years after coronary artery bypass surgery.

Design: In a randomised trial, the no-touch (NT) vein graft in coronary artery bypass surgery has shown a superior patency rate, a slower progression of atherosclerosis and better clinical outcome compared to the conventional $(\mathrm{C})$ vein graft at 8.5 years. All patients at mean time 16 years were offered an echocardiographic and clinical examination.

Results: In the NT-group 34 patients and in the C-group 31 patients underwent an echocardiography examination. A significantly better left ventricle ejection fraction was seen in the NT-group compared to the C-group ( $57.9 \%$ vs $49.4 \% ; p=0.011)$. The size of the left atrium in NT was $21.7 \mathrm{~cm}^{2}$ compared to $23.9 \mathrm{~cm}^{2}$ in $C ; p=0.034$. No patient in NT had atrial fibrillation compared to five patients in $C(p=0.021)$. Patients with a brain natriuretic peptide value (BNP) $\geq 150$ was $30 \%$ in NT compared to $38 \%$ in C. Total mortality was $25 \%$ in NT vs $27 \%$ in C. Cardiac-related deaths were $8 \%$ and $12 \%$ in NT and $\mathrm{C}$ respectively.

Conclusions: The NT vein graft preserves the left ventricular ejection fraction after 16 years. A smaller left atrium, a lower BNP and no atrial fibrillation indicates an improved diastolic left ventricular function in the NT-group.

Trial registration: The study is registered with clinicaltrials.gov (NCT01686100) and The Research and Development registry in Sweden (no. 102841).

\section{INTRODUCTION}

Major problems using vein grafts in coronary artery bypass surgery grafting (CABG) are acute thrombosis and intimal hyperplasia. This leads to a graft occlusion rate of $15-20 \%$ during the first year, ${ }^{1}$ followed by a progressive atherosclerosis that usually starts at $3-5$ years postoperatively, resulting in a graft occlusion rate exceeding $50 \%$ after $10-15$ years and a

\section{KEY MESSAGES}

What is already known about this subject?

- The no-touch vein graft that is harvested with a pedicle of surrounding tissue and not dilated has shown a superior patency, a slower progression of atherosclerosis and a better clinical outcome compared to the conventional vein graft at mean time 8.5 years.

What does this study add?

- No-touch vein grafts preserve left ventricular ejection fraction at 16 years postoperatively.

How might this impact on clinical practice?

- Cardiac surgeons might consider using the no-touch technique in harvesting the vein grafts.

freedom from angina of less than $40 \%$ after 10 years. ${ }^{2-7}$ As a consequence, during the past 10 years there has been a trend towards an increased use of arterial conduits in coronary artery bypass surgery. However, in an ongoing prospective randomised study the new no-touch (NT) vein graft preparation technique has shown a superior patency rate that is comparable to left internal mammary artery (LIMA), a slower progression of atherosclerosis and a better clinical outcome compared to conventional vein grafting at mean time 8.5 years postoperatively. ${ }^{8-10}$

The aim of this study was to investigate the systolic and diastolic left ventricular function as assessed by echocardiography as well as a complete clinical follow-up at mean time 16 years.

\section{MATERIALS AND METHODS}

\section{Study group}

In a randomised prospective study performed 1993-1997 at the Department of 
Cardiothoracic and Vascular Surgery, Örebro University Hospital, Sweden, 156 patients were randomly allocated by a block-randomisation technique ${ }^{11}$ into three groups of 52 patients each for investigating different techniques for harvesting the saphenous vein: in group $\mathrm{C}$ (conventional technique) the saphenous vein was stripped of surrounding tissue and distended for 1 min with a pressure of $300 \mathrm{~mm} \mathrm{Hg}$ (measured on a manometer); in group IM (intermediate) the SV was dissected as in group C. Instead of manual distension, the vein was left in situ and covered with a sponge moistened in salinepapavarine solution; in group NT (no-touch technique) the saphenous vein was harvested together with its cushion of surrounding tissue and was not distended. The saphenous vein was harvested by the same senior surgeon in all of the cases.

A cineangiographic, clinical and an intravascular ultrasound follow-up examination have been performed at mean time 1.5 and 8.5 years postoperatively. ${ }^{8-10} 12$ The local ethics committee approved a third follow-up and patients were included after informed consent was re-obtained at 16 years. All patients alive in the C-group and the NT-group (37 in each group) were offered a follow-up at 16 years postoperatively comprising a complete echocardiographic examination of the heart, including the left ventricular systolic and diastolic function, as well as a complete clinical follow-up assessment of recurrent angina, myocardial infarction, new revascularisation, functional class, risk factors and medical treatment. The examiner was blinded to group assignment. The intermediate group was not followed up at 8.5 and 16 years due to financial limitations and to the fact that this group showed the lowest patency rate at 1.5 years follow-up. ${ }^{12}$

The study is registered with clinicaltrials.gov: NCT01686100 and the Research and Development registry in Sweden: 102841.

\section{Echocardiographic evaluation}

An echocardiographic examination was performed in 34 patients in the NT-group and 31 patients in the C-group. The remaining patients (three patients in the NT-group and six patients in the C-group) were not able to participate in the study and perform the echo examination due to comorbidities (dementia, stroke, blindness and difficulties in walking). The left ventricular ejection fraction (EF) was estimated using the Simpsons modified biplane method in apical four-chamber view and twochamber and a calculation programme in the cardiac ultrasound machine automatically calculated the EF as ( (end diastolic volume-end systolic volume)/end diastolic volume $) \times 100$. The size of the left and right atrium in $\mathrm{cm}^{2}$ was calculated in the four-chamber view by tracing the areas manually at end systole using a caliper incorporated in the echo system. The size of the atriums was also corrected for the body surface.

The left ventricular diastolic function was assessed by evaluating the E-wave (early phase) and A-wave (atrium contraction) Doppler signal $(\mathrm{m} / \mathrm{s})$ of the blood flow over the mitral valve during diastole in the four-chamber view. The E/A-ratio was calculated. The tissue-Doppler signal amplitude $\left(\mathrm{e}^{\prime}\right)$ was assessed from the myocardium just below the atrioventricular-plane in the left ventricle in the four-chamber view. The $\mathrm{E} / \mathrm{e}^{\prime}$-ratio was also calculated; $\mathrm{E}$ is the maximal flow velocity in the early mitral inflow in the left ventricle and the $\mathrm{e}^{\prime}$ is the average of the septal and lateral tissue-Doppler signal amplitude in the position above. A commercially available echocardiography system GE Vivid E 9 ultrasound system from GE Healthcare, General Electric Company, USA was used and a $3.5 \mathrm{MHz}$ transducer. All measurements were performed using the incorporated calculation programme in the ultrasound machine.

\section{Clinical evaluation}

The 16 years clinical outcome of all patients in the C-group and NT-group was established. In deceased patients the cause of death was established from the Swedish death registry and patient files. Thirty-seven patients in both groups underwent a clinical follow-up. The patients were assessed with respect to recurrent angina using the CCS (Canadian Cardiovascular Society)-classification I-IV, functional class using the New York Heart Association (NYHA)-classification I-IV, occurrence of myocardial infarction and new revascularisation during the follow-up period. Cardiovascular risk factors, complete lipid status, $\beta$-glucose, brain natriuretic peptide (BNP) and blood pressure were established. Hypertension was defined as blood pressure $>140$ / $90 \mathrm{~mm} \mathrm{Hg}$, low-density lipoprotein (LDL) $>2.5 \mathrm{mmol} / \mathrm{L}$ was considered as hyperlipidaemia. A BNP value $\geq 150 \mathrm{ng} / \mathrm{L}$ was defined as having the highest diagnostic accuracy. ${ }^{13}$

\section{Statistical analysis}

Differences between the two randomised groups were tested with Student's t test for independent samples as concerns quantitative variables assumed to follow a normal distribution. An analysis for all three time-points simultaneously was performed with a General Linear Model (GLM) for repeated measures as concerns the EF. In this analysis the gradient over whole follow-up period from preoperative status to 16 years was analysed for group differences in slope. This analysis was supplemented with Student t test for each one of the evaluation time-points and in this case the Bonferroni correction for multiple testing was applied. Student t-test was also applied for analysis of other clinical outcomes but then only for the available data at the 16-years follow-up. For qualitative variables as well as dichotomous variables Fisher's exact test and extensions of the Fisher test was applied. We performed this analysis with algorithms especially adopted for small samples. p Values $<0.05$ are considered statistically significant. The statistical programs StatXact, V.8 (http://www.cytel.com/ software/statxact) and SPSS, V.20 (http://www.ibm. 
com/software/se/analytics/spss/) were used for the computations.

\section{RESULTS}

The basic clinical characteristics of the patients at 16 years follow-up are presented in table 1 .

The number of smokers was low, the number of patients with hypertension $(>140 / 90 \mathrm{~mm} \mathrm{Hg}$ ) was high as well as the number of patients with fasting $\beta$-glucose $>6.1 \mathrm{mmol} / \mathrm{L}$ (impaired fasting glycaemia) although the number of patients with known diabetes was lower. Patients with a BNP value $\geq 150$ was $30 \%$ in NT compared to $38 \%$ in C. The use of $\beta$-blockers was high and the use of aspirin and statins were very high in both groups. The serum-LDL (S-LDL) levels were elevated in both groups, $2.5 \pm 0.8 \mathrm{mmol} / \mathrm{L}$ in group NT and 2.7 $\pm 1.1 \mathrm{mmol} / \mathrm{L}$ in group-C. However, there were no statistically significant differences in the cardiac risk factors or medication between the two groups.

\section{Echocardiographic results}

The results are seen in table 2. In the NT-group 34 out of 37 patients and in the C-group 31 out of 37 patients underwent an echocardiography examination.

Figure 1 shows the mean ejection fraction and its gradient for all patients who underwent EF-estimation preoperative, after 8.5 years and after 16 years. The GLM analysis with repeated measures for all three occasions showed a significant group difference, $\mathrm{p}=0.034$ regarding the slope of the gradient. This result was due to the lower decline over the 16 years for the NT-group and at the last evaluation the EF for the NT -group was 57.9 $\pm 9.5 \%$ and for the C-group $49.4 \pm 13.3 \%$, with a Bonferroni adjusted $p$ value of 0.011 for group difference. All 34 patients in the NT-group had sinus rhythm compared to 26 out of $31(83.9 \%)$ in the C-group $(p=0.021)$. In the patients with sinus rhythm and no mitral valve disease the left atrium was significantly larger in the C-group $\left(23.9 \pm 3.4 \mathrm{~cm}^{2}\right)$ compared to $(21.7$ $\left.\pm 4.3 \mathrm{~cm}^{2}\right)$ in the NT-group $(\mathrm{p}=0.034)$ even when the size

Table 1 Clinical characteristics at 16 years follow-up

\begin{tabular}{|c|c|c|}
\hline & No-touch group & Conventional group \\
\hline Randomised patients at start of study (n) & 52 & 52 \\
\hline Mortality after 16 years follow-up, n (\%) & $13(25)$ & $14(27)$ \\
\hline Loss to follow-up (n) & 2 & 1 \\
\hline Patients at 16 years follow-up $(n)$ & 37 & 37 \\
\hline \multicolumn{3}{|l|}{ Characteristics for patients at 16 years } \\
\hline Age, mean $\pm S D$ & $74.7 \pm 5.5$ & $72.9 \pm 7.2$ \\
\hline Male, n (\%) & $35(94.6)$ & $30(81.1)$ \\
\hline \multicolumn{3}{|l|}{ Risk factors } \\
\hline Family history, n (\%) & $21(56.8)$ & $26(70.3)$ \\
\hline Previous AMI, n (\%) & $20(54.1)$ & $20(54.1)$ \\
\hline Smokers, n (\%) & $4(10.8)$ & $5(13.5)$ \\
\hline Diabetes, n (\%) & $11(29.7)$ & $9(24.3)$ \\
\hline Hyperlipidaemia, n (\%) & 36 (97.3) & $33(89.2)$ \\
\hline Hypertension, n (\%) & $19(51.4)$ & $20(54.1)$ \\
\hline \multicolumn{3}{|l|}{ Blood chemistry: } \\
\hline S-cholesterol $(\mathrm{mmol} / \mathrm{L})$, mean $\pm \mathrm{SD}$ & $4.7 \pm 1.0$ & $4.7 \pm 1.1$ \\
\hline $\mathrm{S}-\mathrm{LDL}(\mathrm{mmol} / \mathrm{L})$, mean $\pm \mathrm{SD}$ & $2.5 \pm 0.8$ & $2.7 \pm 1.1$ \\
\hline $\mathrm{S}-\mathrm{HDL}(\mathrm{mmol} / \mathrm{L})$, mean $\pm \mathrm{SD}$ & $1.2 \pm 0.3$ & $1.1 \pm 0.2$ \\
\hline S-Triglycerides (mmol/L), mean $\pm S D$ & $2.1 \pm 1.0$ & $1.8 \pm 0.9$ \\
\hline$\beta$-glucose $>6.1 \mathrm{mmol} / \mathrm{L}, \mathrm{n}(\%)$ & $20 / 34(58.8 \%)$ & $13 / 31(41.9 \%)$ \\
\hline BNP $\geq 150$ ng/L, n (\%) & $10 / 33(30.3 \%)$ & $11 / 29(37.9 \%)$ \\
\hline Blood pressure (>140/90 mm Hg), n (\%) & $11(29.7)$ & $8(21.6)$ \\
\hline \multicolumn{3}{|l|}{ Medical treatment } \\
\hline$\beta$-blockers, n (\%) & $28(75.7)$ & $29(78.4)$ \\
\hline Ca-inhibitor, n (\%) & $10(27)$ & $8(21.6)$ \\
\hline ASA, $n(\%)$ & $35(94.6)$ & 34 (91.9) \\
\hline Statins, n (\%) & $35(94.6)$ & $32(86.5)$ \\
\hline Nitrates, n (\%) & $5(13.5)$ & $8(21.6)$ \\
\hline Diuretics, n (\%) & $8(21.6)$ & 7 (18.9) \\
\hline ACE-inhibitor or All blockade n (\%) & $16(43.2)$ & $22(59.5)$ \\
\hline Peroral diabetic medication, $\mathrm{n}(\%)$ & $4(10.8)$ & $3(8.1)$ \\
\hline Insulin diabetic medication, $\mathrm{n}(\%)$ & $3(8.1)$ & $0(0)$ \\
\hline Both peroral and insulin, $\mathrm{n}(\%)$ & $4(10.8)$ & $6(16.2)$ \\
\hline
\end{tabular}


Table 2 Echocardiography results in patients at 16 years follow-up. Mean values $\pm S D$ except for $E / e^{\prime}$ ratio $>15$, where $n$ and per cent are used

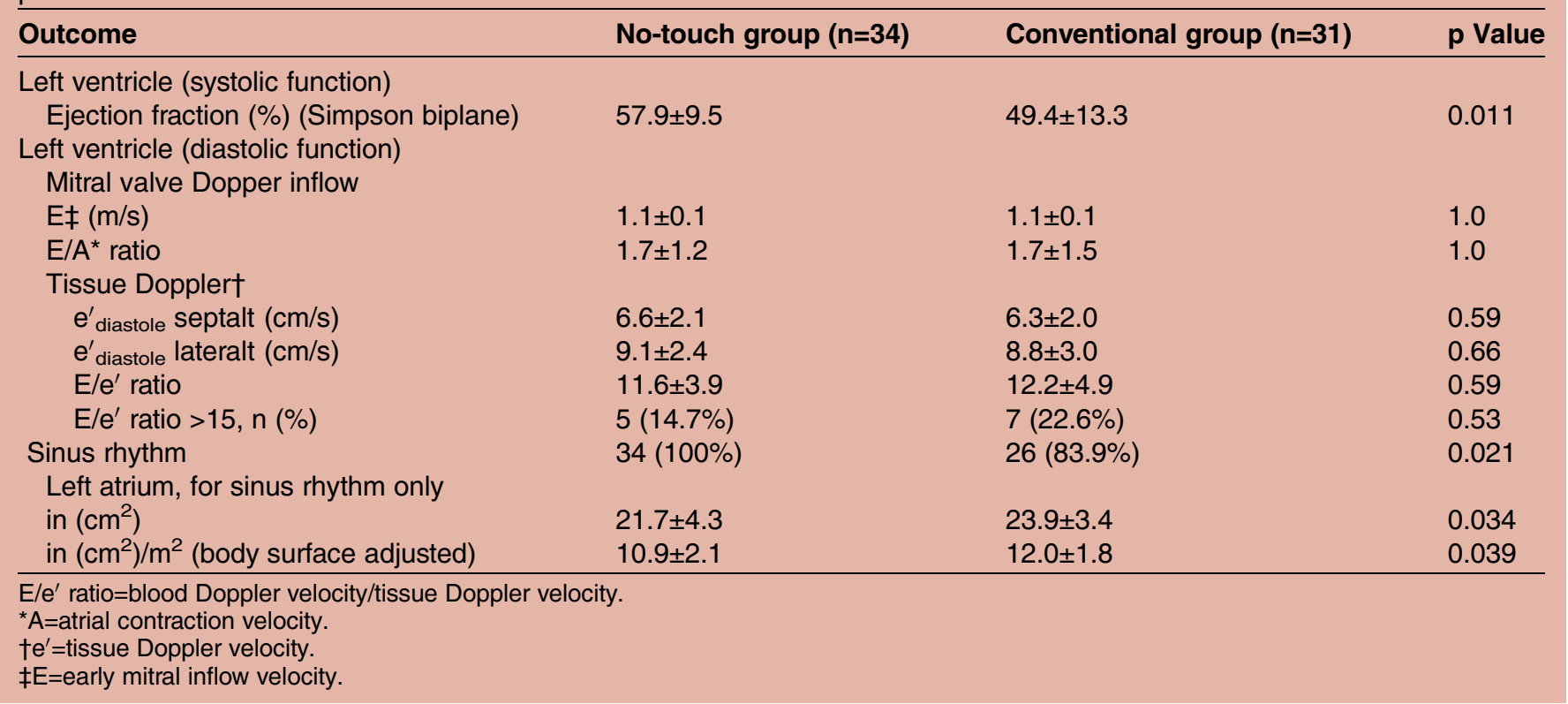

of the left atrium was corrected for the body surface $\left(12.0 \pm 1.8 \mathrm{~cm}^{2}\right.$ vs $\left.10.9 \pm 2.1 \mathrm{~cm}^{2 ;} \mathrm{p}=0.039\right)$.

Tissue Doppler results as well as the mitral valve inflow expressed as E, E/A-ratio and the $\mathrm{E} / \mathrm{e}^{\prime}$-ratio are presented in table 2. There were no significant differences in any of these variables between the two groups.

\section{Clinical outcome}

Total mortality was $27 \%(14 / 52)$ in group $\mathrm{C}$ and $25 \%$ $(13 / 52)$ in NT (table 3$)$. The cause of death was established from the Swedish death registry and patient files. Eight patients in $\mathrm{C}$ and nine patients in NT died from non-cardiac-related causes (cancer, renal failure, lung fibrosis, ruptured abdominal aortic aneurysm, infectious diseases or stroke).

Six cardiac-related deaths in group C, $12 \%$ (two acute myocardial infarction, four heart failure) and four in group NT, 8\% (three acute myocardial infarction and one heart failure).

Recurrent angina occurred in 14 patients in the NT-group compared to 17 patients in the C-group. Five of the patients in the NT-group suffered from an acute myocardial infarction compared to 10 patients in the C-group $(p=0.27)$. Ten patients in the NT-group underwent an ischaemia-driven cine-angiogram compared to 13 patients in the C-group. Eight patients in both groups had a PCI-revascularisation either in a vein graft, native coronary artery or both. In the remaining patients no PCI procedure was possible and they were treated medically.

Twenty-three patients in the NT-group were free from angina compared to 20 patients in the C-group. In the NT-group, 18 patients out of 23 were classified as NYHA-class I versus 10 patients out of 20 in the C-group.
However, this difference may be misleading due to other comorbidities such as stroke, intermittent claudication, back pain, hip and knee problems which greatly impacted the physical capabilities of these patients.

\section{DISCUSSION}

The primary observation of this study is that the left ventricular systolic function in the NT-group is persevered at mean time 16 years. This is in line with our earlier

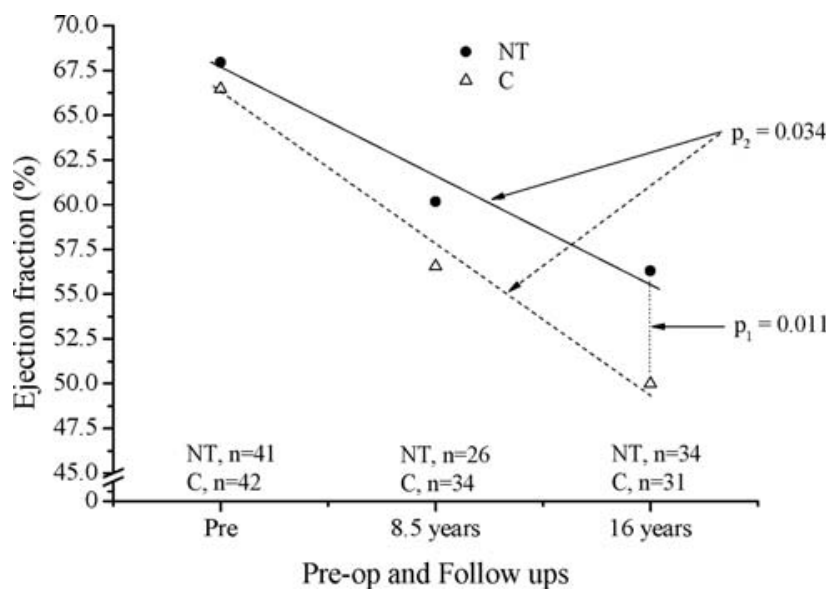

Figure 1 Ejection fraction preoperatively and at follow-up in conventional (C) and no-touch (NT) groups. Statistical significance for difference between groups at 16-year follow-up, adjusted for prevalues, is shown by 1 . Lines indicate gradient for ejection fraction from preoperation to 16-year follow-up and p2 shows statistical significance between groups with respect to gradient. Two hundred and eight observations on ejection fraction for 83 patients, number of observations for each assessment is shown in the figure. 
Table 3 Clinical outcome at 16-year follow-up

\begin{tabular}{lccc}
\hline Patients and outcome & No-touch group & Conventional group & p Value* \\
\hline Included at study start, $\mathrm{n}$ & 52 & 52 & \\
Total mortality, $\mathrm{n}(\%)$ & $13(25)$ & $14(27)$ & 1.00 \\
Of which were cardiac related & $4(8)$ & $6(12)$ & \\
Loss to follow-up at 16 years, $\mathrm{n}$ & 2 & 1 & 0.68 \\
Follow-up at 16 years, $\mathrm{n}$ & 37 & 37 & 0.27 \\
Recurrent angina, $\mathrm{n}(\%)$ & $14(38)$ & $17(46)$ & 0.64 \\
Acute myocardial infarction, $\mathrm{n}(\%)$ & $5(14)$ & $13(27)$ & 1.00 \\
Ischaemia driven cine-angiogram, $\mathrm{n}(\%)$ & $10(27)$ & $8(22)$ & 0.85 \\
Percutaneous coronary intervention, $\mathrm{n}(\%)$ & $8(22)$ & $20(54)$ & 0.46 \\
Angina-free patients, $\mathrm{n}(\%)$ & $23(62)$ & $10(50)$ & \\
NYHA-class I, $\mathrm{n}(\%)$ & $18(78)$ & & \\
"Statistical significance by Fisher's exact test. & & & \\
NYHA, New York Heart Association. & & &
\end{tabular}

findings by intravascular ultrasound, ${ }^{10}$ at 8.5 years that the process of atherosclerosis is delayed in the vein grafts prepared using the no-touch technique. The improved patency rate is the most likely cause of this preserved left ventricular EF in the NT-group as there were no difference between the two groups according to known cardiac risk factors including lipid status.

Compared with a well-known long-term follow-up study using mostly arterial revascularisation, Achouh et $a l^{14}$ reported a lower EF after 9.2 years, $55 \%$ compared to $56.7 \%$ preoperative, $\mathrm{p}=0.02$.

The evaluation of the diastolic left ventricle function is very complex and can only be achieved clinically in less than one-half of patients, ${ }^{15}$ even in the hands of experts. ${ }^{16}{ }^{17}$ In this study it is possible to obtain some indication of the diastolic function. Atrial size has been a surrogate for diastolic dysfunction in patients with normal left ventricular systolic function. ${ }^{18-21}$ Diastolic dysfunction has also been shown to predict atrial fibrillation. ${ }^{21}$ In this study the patients in the NT-group had a significantly lower left atrial size $(p=0.034)$, the percentage of patients with a BNP $\geq 150$ was lower in the NT-group and no patients in the NT-group suffered from atrial fibrillation versus $16.1 \%$ of patients in the C-group $(\mathrm{p}=0.021)$. This suggests a trend for a higher degree of diastolic dysfunction in the C-group.

Already by 8.5 years of clinical follow-up there were significantly more asymptomatic patients in the NT-group. ${ }^{9}$ At 16 years this pattern seems to continue, although not statistically significant and the comorbidities of the patients decrease the absolute benefit. The number of patients with recurrent angina was higher in the C-group and the number of patients suffering from an acute myocardial infarction was also doubled in the C-group, despite the fact that there was no difference between the two groups in the treatment of the known risk factors. The percentage of cardiac-related deaths was $12 \%$ in C-group and $8 \%$ in NT. However, there was no difference in PCI-revascularisation. We think that the issue of whether hard cardiac end points are influenced by NT vein grafting will be addressed in an ongoing multicenter study, where a larger number of patients will be studied. (SUPERIOR-SVG, clinicaltrials.gov: NCT01047449)

If we want to compare the clinical long-term results for the patients in the NT-group with total arterial revascularisation reported by others, ${ }^{22-24}$ we must make the comparison after approximately 8 years, the longest present follow-up for most all-arterial studies. The arterial revascularisation studies have shown a 7 -year survival rate of $88-91 \%$ compared to $94 \%$ in group NT, freedom from cardiac death was $92-96 \%$ vs $100 \%$ in group NT, freedom from myocardial infarction $92-97 \%$ vs $98 \%$ in group NT, freedom from recurrent angina $85-92 \%$ vs $75 \%$ in group NT, freedom from any cardiac event 78 $85 \%$ vs $74 \%$ in group NT. Puskas et al, ${ }^{25}$ showed that the use of bilateral internal thoracic artery had a significantly increased survival rate at 8 years compared to the usage of a single internal thoracic artery $(89.3 \%$ vs $68.3 \%)$ irrespective the diabetic status of the patients. Achouh et al, ${ }^{14}$ had a total survival rate of $80 \%$ and a cardiac-related mortality of $7 \%$ after 9.2 years.

Locker $e t a l,{ }^{26}$ showed (in matched groups) a significantly better 15 -year survival in the arterial revascularisation group compared to the LIMA+saphenous vein group $(70 \%$ vs $60 \%)$. The cardiac-related mortality was not commented in this study. In our study the 16 years survival was $75 \%$ in NT and $73 \%$ in C with $8 \%$ and $12 \%$ cardiac-related mortality respectively.

It is well known that the treatment of the traditional risk factors after CABG is extremely important to slow down the atherosclerotic process in the vein grafts and the native coronary arteries. In this study we found at 16 years a low number of smokers, $10-15 \%$, but the number of patients with hypertension, although treated, was as high as $20-30 \%$ and the amount of patients with elevated fasting $\beta$-glucose $>6.1 \mathrm{mmol} / \mathrm{L}$ was high in both groups. This by definition is considered to be impaired fasting glycaemia and is a known risk for future development of diabetes and cardiovascular disease.

Probably the most important risk factor is the lipid levels. Despite a high number of patients treated with statins $(94.6 \%$ in group NT-group and $86.5 \%$ in group 
C), the S-LDL levels were still elevated in both groups, $(2.5-2.7 \mathrm{mmol} / \mathrm{L})$. However, this was a significant improvement compared to the results from 8.5 years follow-up in the same study where the LDL level was $3.2-3.4 \mathrm{mmol} / \mathrm{L}$. The percentage of patients reaching LDL $\leq 2.5 \mathrm{mmol} / \mathrm{L}$ was $53.9 \%$ in the NT-group and $61.3 \%$ in the C-group at 16-year follow-up, compared to only about $25 \%$ after 8.5 years. This improvement in lipid control is important since a previous post-CABG trial showed that aggressive reduction of LDL-cholesterol below $2.5 \mathrm{mmol} / \mathrm{L}$, compared to moderate lowering to about $3.5 \mathrm{mmol} / \mathrm{L}$, significantly reduced the progression of atherosclerosis in grafts. ${ }^{27}$ However, the accepted goal for optimal LDL-treatment according to European guidelines from 2010 in this category of patients is $\leq 1.8 \mathrm{mmol} / \mathrm{L}$. This is obtained in $20-25 \%$ of the patients in both groups at 16-year follow-up.

We have no doubt that the preparation of saphenous vein grafts plays a vital role in the long-term result of CABG and that harvesting the grafts with the no-touch technique is a crucial step in that direction. This has even been mentioned in the latest ESC/EACTS guidelines 2014 on myocardial revascularisation, where the no-touch technique is recommended if the saphenous vein is harvested with an open technique.

\section{Limitations of the study}

The major limitation of this study is its small size. The study was initially designed to evaluate differences in graft patency between the NT-group and the C-group and not differences in the clinical or echocardiographic outcomes. Some preoperative baseline data were not available at the last follow-up and could not be accounted for in the final analysis. We also would like to mention that three patients in the NT-group and six in C-group did not perform the echocardiography at 16 years due severe comorbidities that hindered them from participating in the study. The statistical analysis was performed only on 34 patients in NT and 31 in C and did not account for the nine missing patients. We can only speculate that if the remaining very ill patients had been able to perform the echocardiography we would have obtained a lower EF for most of them with a bigger chance of increasing the differences between the groups (three in NT and six in C), that is, if the missing patients caused a bias it would probably favour the conventional group.

Some concerns have been raised about the conventional harvesting technique in this study. It is not unusual to dilate the saphenous vein to $300 \mathrm{~mm} \mathrm{Hg}$ or more especially when dealing with small-caliber vessels with severe spasm after harvesting. A recent study showed a pressure rise under manual dilation of saphenous veins to $>200 \mathrm{~mm} \mathrm{Hg}$ in $29 \%$ of cases, $>300 \mathrm{~mm} \mathrm{Hg}$ in $16 \%$ of cases and $>400 \mathrm{~mm} \mathrm{Hg}$ in $21 \%$ of cases (the individuals performing the harvesting were totally blinded about the amount of pressure that was reached during distention 2). ${ }^{28}$ Another study mentioned that the saphenous veins are dilated to over $600 \mathrm{~mm} \mathrm{Hg}$ before implantation. ${ }^{29}$ However, recent awareness of the mechanical damage caused by manual dilation has probably led to a more gentle approach during the preparation of the saphenous vein. In our study, the patency rate of the conventionally harvested veins was $89 \%$ after 1.5 years and $77 \%$ after 8.5 years. ${ }^{8}{ }^{12}$ This is higher than what previously has been reported (10-years patency rate of the saphenous vein graft is about $40-60 \%) .{ }^{5}$

\section{CONCLUSION}

The long-term echocardiographic follow-up showed that the NT vein harvesting technique provides a preserved left ventricular $\mathrm{EF}$ after mean time 16 years and an inferred improved left ventricular diastolic function as compared to the conventional harvesting technique in CABG.

Acknowledgements The authors thank the nurses and staff at the Department of Cardiothoracic and Vascular Surgery, Örebro University Hospital for taking care of our patients.

Contributors All authors have actively contributed to the planning, conduct and reporting of this article.

Funding This study was supported by Örebro County Council through the regional research board and Nyckelfonden.

Competing interests None.

Patient consent Obtained.

Ethics approval The study was approved by the local ethical committee in Örebro, Sweden and performed in accordance to the Declaration of Helsinki.

Provenance and peer review Not commissioned; externally peer reviewed.

Open Access This is an Open Access article distributed in accordance with the Creative Commons Attribution Non Commercial (CC BY-NC 4.0) license, which permits others to distribute, remix, adapt, build upon this work noncommercially, and license their derivative works on different terms, provided the original work is properly cited and the use is non-commercial. See: http:// creativecommons.org/licenses/by-nc/4.0/

\section{REFERENCES}

1. Goldman S, Copeland J, Moritz T, et al. Saphenous vein graft patency 1 year after coronary artery bypass surgery and effects of antiplatelet therapy. Results of a Veterans Administration Cooperative Study. Circulation 1989;80:1190-7.

2. Bourassa MG. Long-term vein graft patency. Curr Opin Cardiol 1994;9:685-91.

3. Campeau L, Enjalbert M, Lesperance J, et al. The relation of risk factors to the development of atherosclerosis in saphenous-vein bypass grafts and the progression of disease in the native circulation. A study 10 years after aortocoronary bypass surgery. N Engl J Med 1984;311:1329-32.

4. Fitzgibbon GM, Kafka HP, Leach AJ, et al. Coronary bypass graft fate and patient outcome: angiographic follow-up of 5,065 grafts related to survival and reoperation in 1,388 patients during 25 years. J Am Coll Cardiol 1996;28:616-26.

5. Goldman S, Zadina K, Moritz T, et al. Long-term patency of saphenous vein and left internal mammary artery grafts after coronary artery bypass surgery: results from a Department of Veterans Affairs Cooperative Study. J Am Coll Cardiol 2004;44:2149-56.

6. Lytle BW, Loop FD, Cosgrove DM, et al. Long-term (5 to 12 years) serial studies of internal mammary artery and saphenous vein coronary bypass grafts. J Thorac Cardiovasc Surg 1985;89:248-58.

7. Shah PJ, Gordon I, Fuller J, et al. Factors affecting saphenous vein graft patency: clinical and angiographic study in 1402 symptomatic patients operated on between 1977 and 1999. J Thorac Cardiovasc Surg 2003;126:1972-7. 
8. Souza DS, Johansson B, Bojo L, et al. Harvesting the saphenous vein with surrounding tissue for CABG provides long-term graft patency comparable to the left internal thoracic artery: results of a randomized longitudinal trial. J Thorac Cardiovasc Surg 2006;132:373-8.

9. Johansson BL, Souza DS, Bodin L, et al. No touch vein harvesting technique for CABG improves the long-term clinical outcome. Scand Cardiovasc J 2009;43:63-8.

10. Johansson BL, Souza DS, Bodin L, et al. Slower progression of atherosclerosis in vein grafts harvested with 'no touch' technique compared with conventional harvesting technique in coronary artery bypass grafting: an angiographic and intravascular ultrasound study. Eur J Cardiothorac Surg 2010;38:414-19.

11. Altman DG, Bland JM. How to randomise. BMJ 1999;319:703-4.

12. Souza DS, Dashwood MR, Tsui JC, et al. Improved patency in vein grafts harvested with surrounding tissue: results of a randomized study using three harvesting techniques. Ann Thorac Surg 2002;73:1189-95.

13. Maisel AS, Krishnaswamy P, Nowak RM, et al. Rapid measurement of B-type natriuretic peptide in the emergency diagnosis of heart failure. N Engl J Med 2002;347:161-7.

14. Achouh P, Isselmou KO, Boutekadjirt R, et al. Reappraisal of a 20-year experience with the radial artery as a conduit for coronary bypass grafting. Eur J Cardiothorac Surg 2012;41:87-92.

15. Lubien E, DeMaria A, Krishnaswamy $P$, et al. Utility of B-natriuretic peptide in detecting diastolic dysfunction: comparison with Dopple velocity recordings. Circulation 2002;105:595-601.

16. Aljaroudi $\mathrm{W}$, Alraies MC, Halley $\mathrm{C}$, et al. Impact of progression of diastolic dysfunction on mortality in patients with normal ejection fraction. Circulation 2012;125:782-8.

17. Kane GC, Karon BL, Mahoney DW, et al. Progression of left ventricular diastolic dysfunction and risk of heart failure. JAMA 2011;306:856-63.

18. Abhayaratna WP, Seward JB, Appleton CP, et al. Left atrial size: physiologic determinants and clinical applications. J Am Coll Cardiol 2006;47:2357-63.

19. De Castro S, Caselli S, Di Angelantonio E, et al. Relation of left atrial maximal volume measured by real-time $3 \mathrm{D}$ echocardiography to demographic, clinical, and Doppler variables. Am J Cardiol 2008;101:1347-52.

20. Tsang TS, Barnes ME, Gersh BJ, et al. Left atrial volume as a morphophysiologic expression of left ventricular diastolic dysfunction and relation to cardiovascular risk burden. Am J Cardiol 2002;90:1284-9.

21. Tsang TS, Gersh BJ, Appleton CP, et al. Left ventricular diastolic dysfunction as a predictor of the first diagnosed nonvalvular atrial fibrillation in 840 elderly men and women. J Am Coll Cardiol 2002;40:1636-44

22. Acar C, Ramsheyi A, Pagny JY, et al. The radial artery for coronary artery bypass grafting: clinical and angiographic results at five years. J Thorac Cardiovasc Surg 1998;116:981-9.

23. Possati G, Gaudino M, Alessandrini F, et al. Midterm clinical and angiographic results of radial artery grafts used for myocardial revascularization. J Thorac Cardiovasc Surg 1998;116:1015-21.

24. Sergeant $P$, Blackstone $E$, Meyns $B$. Is return of angina after coronary artery bypass grafting immutable, can it be delayed, and is it important? J Thorac Cardiovasc Surg 1998;116:440-53.

25. Puskas JD, Sadiq A, Vassiliades TA, et al. Bilateral internal thoracic artery grafting is associated with significantly improved long-term survival, even among diabetic patients. Ann Thorac Surg 2012;94:710-15; discussion 15-6.

26. Locker C, Schaff HV, Dearani JA, et al. Multiple arterial grafts improve late survival of patients undergoing coronary artery bypass graft surgery: analysis of 8622 patients with multivessel disease. Circulation 2012;126:1023-30.

27. Campeau L, Hunninghake DB, Knatterud GL, et al. Aggressive cholesterol lowering delays saphenous vein graft atherosclerosis in women, the elderly, and patients with associated risk factors. NHLBI post coronary artery bypass graft clinical trial. Post CABG Trial Investigators. Circulation 1999;(25):3241-7.

28. Khaleel MS, Dorheim TA, Duryee MJ, et al. High-pressure distention of the saphenous vein during preparation results in increased markers of inflammation: a potential mechanism for graft failure. Ann Thorac Surg 2012;93:552-8.

29. Li FD, Eagle $\mathrm{S}$, Brophy $\mathrm{C}$, et al. Pressure control during preparation of saphenous veins. JAMA Surg 2014;655-62. 